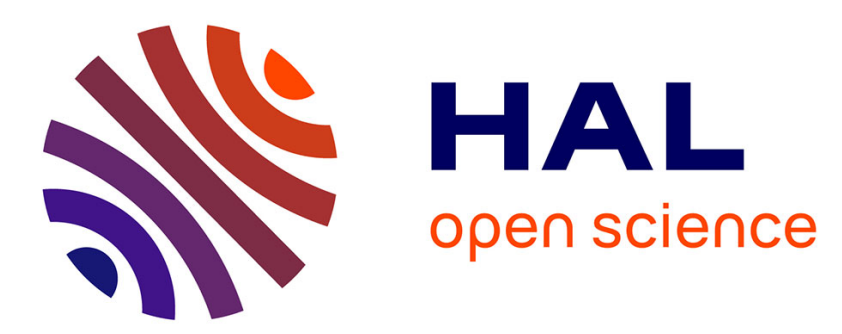

\title{
Sweet and sour discrimination abilities of elderly people compared to those of young adults in apple purée
}

M. Mingioni, E. Mehinagic, K. Siucińska, D. Konopacka, G. Artigas, Ronan Symoneaux, I. Maitre

\section{- To cite this version:}

M. Mingioni, E. Mehinagic, K. Siucińska, D. Konopacka, G. Artigas, et al.. Sweet and sour discrimination abilities of elderly people compared to those of young adults in apple purée. Food Quality and Preference, 2017, 59, pp.59-67. 10.1016/j.foodqual.2017.02.007 . hal-01604280

\section{HAL Id: hal-01604280 \\ https://hal.science/hal-01604280}

Submitted on 25 May 2020

HAL is a multi-disciplinary open access archive for the deposit and dissemination of scientific research documents, whether they are published or not. The documents may come from teaching and research institutions in France or abroad, or from public or private research centers.
L'archive ouverte pluridisciplinaire HAL, est destinée au dépôt et à la diffusion de documents scientifiques de niveau recherche, publiés ou non, émanant des établissements d'enseignement et de recherche français ou étrangers, des laboratoires publics ou privés. 


\title{
Sweet and sour discrimination abilities of elderly people compared to those of young adults in apple purée
}

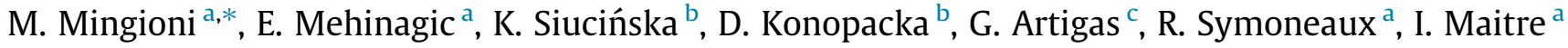 \\ a Unité de Recherche GRAPPE, Univ Bretagne Loire, Ecole Supérieure d'Agricultures (ESA)-INRA, 55 rue Rabelais, BP 30748, 49007 Angers Cedex, France \\ ${ }^{\mathrm{b}}$ Research Institute of Horticulture, Konstytucji 3 Maja 1/3 Str., 96-100 Skierniewice, Poland \\ ${ }^{\mathrm{c}}$ Emporhotel, AIE, C/Hospital, 27, 2on, 1a, 17230 Palamós, Spain
}

\section{A R T I C L E I N F O}

\section{Article history:}

Received 20 June 2016

Received in revised form 3 February 2017

Accepted 4 February 2017

Available online 10 February 2017

\section{Keywords:}

Gustation

Independently-living elderly

Apple purée

Food matrix

Sucrose

Malic acid

\begin{abstract}
A B S T R A C T
The number of elderly people is growing in Europe. A decrease in gustatory capacities (detection, identification, discrimination) is associated with aging. In the literature, discrimination abilities have been studied mainly in aqueous model solutions, but less is known about sensitivity in real food matrices. Moreover, in foods, taste interactions can occur and modify perceptions (masking effect). This study aimed to compare the discrimination abilities of elderly people and younger adults when tasting apple purées and hypothesized that: discrimination abilities are lower in a group of elderly people (H1) and that taste interactions can modify discrimination performances (H2). A total of 105 young adults (18-40 years-old) and 130 elderly people (65+ years-old) were recruited in France and Poland. Their discrimination abilities were measured for sweet and sour tastes in apple purées. Pairs of apple purées with different sugar/acid concentrations were presented to participants and they were asked to indicate the sweetest/sourest sample. The results showed that the performances of the elderly people group were as good as those of the young adults group for sweetness $\left(\mathrm{chi}^{2}=0.036, \mathrm{p}=0.850\right)$ and sourness $\left(\mathrm{chi}^{2}=0.271, \mathrm{p}=0.603\right.$ ) discrimination. For both groups, a difference of $10 \mathrm{~g} / \mathrm{kg}$ of sucrose or $0.25 \mathrm{~g} / \mathrm{kg}$ of malic acid was enough to discriminate two samples $(\mathrm{p}<0.001)$. In our experimental conditions, no significant masking effect was found. These results could help food industries to develop new fruit-based foods that match the sensory perceptions of elderly people.
\end{abstract}

(c) 2017 Elsevier Ltd. All rights reserved.

\section{Introduction}

Europe needs to tackle the problems of an aging population and to ensure that the elderly population is well fed. Aging is associated with a decrease in sensory perceptions (Kremer, 2008; Methven, Allen, Withers, \& Gosney, 2012; Sulmont-Rossé, Maitre, \& Issanchou, 2010) and it is assumed that these sensory losses could be related to a loss of appetite and less pleasure in eating (Roberts \& Rosenberg, 2006).

Researchers have shown an overall decline in sensory perceptions with age, mainly in detection and identification abilities. A decrease in olfactory performances with age is well established (Doty et al., 1984; Kaneda et al., 2000; Kremer, Bult, Mojet, \& Kroeze, 2007; Murphy, Cain, Gilmore, \& Skinner, 1991; Schiffman \& Pasternak, 1979; Stevens \& Dadarwala, 1993; Sulmont-Rossé et al., 2015), but masks an important inter-individual variability (Kremer et al., 2007; Stevens \& Dadarwala, 1993; Sulmont-Rossé

\footnotetext{
* Corresponding author.

E-mail address: mathieu.mingioni@gmail.com (M. Mingioni).
}

et al., 2015). As with olfaction, aging is associated with a decrease in taste perceptions. This has been demonstrated for detection abilities in salty and sour solutions (Kaneda et al., 2000; Kremer et al., 2007; Methven et al., 2012; Mojet, Christ-Hazelhof, \& Heidema, 2001) but the results are more divergent for sweet and bitter solutions (Kaneda et al., 2000; Kremer et al., 2007; Methven et al., 2012; Mojet et al., 2001) and also when tested in real foods (Schiffman, Sattely-Miller, Zimmerman, Graham, \& Erickson, 1994). Perceived intensities also seem to decrease with age for the five tastes dissolved in solutions but only for sweet and salty tastes in real food (Mojet, Heidema, \& Christ-Hazelhof, 2003).

Regarding the impact of age on gustatory discrimination, the results are scarcer and contradictory. On the one hand, authors have studied discrimination using model solutions. Kaneda et al. (2000) compared the discrimination performances of 20 young adults (21-40 years-old) and 20 elderly people (59-75 years-old). Using a 3-AFC procedure, participants tasted model solutions with different sugar/acid ratios and had to find the sample that differed from the two others. The results showed that, for sweet and sour 
mixtures, discrimination abilities were lower for elderly people. In contrast, Gilmore and Murphy (1989) showed that the discrimination abilities of 12 elderly women were preserved for sweet solutions but were lower than those of young people for bitter solutions. Elderly people needed a larger difference in bitterness between two samples to differentiate them. On the other hand, Mojet et al. (2003) studied the discrimination abilities of 21 elderly people when consuming real foods: iced tea, chocolate drink, mayonnaise, tomato soup and bouillon. Using triangle tests, participants had to pick the odd sample out of three. Interestingly, the results highlighted that "intensity discrimination seems to be remarkably resistant to the effect of aging". Given these contradictory results, the impact of aging on gustatory discrimination abilities still remains unclear and is worth being further explored.

Mojet et al. (2003) showed that the results are matrixdependent (model solutions versus real foods). Thus, the relevance of determining gustatory discrimination abilities of taste compounds dissolved in water may be limited for predicting performances in real foods. Taste-taste interactions that occur in real foods can modify gustatory perceptions. They have been well studied in model solutions (see Keast and Breslin (2002) and Green, Lim, Osterhoff, Blacher, \& Nachtigal (2010), for a complete review). It is established that mutual masking effects can occur between sweet and sour tastes. Researchers have shown that, when diluted in water, a sweet taste reduces sour perception and a sour taste reduces sweet perception (Pelletier, Lawless, \& Horne, 2004; Stevens, 1996). In 2004, Mojet, Heidema, \& Christ-Hazelhof studied the impact of taste-taste interactions on side tastes perceived when consuming real foods (Mojet, Heidema and ChristHazelhof, 2004). Five commercial products were chosen to be typical of one taste: iced tea (sweet), mayonnaise (sour), chocolate drink (bitter), tomato soup (salty) and bouillon (umami). Taste modifications were applied to each product (sweet variation for iced tea, sour variation for mayonnaise, etc.). For each product, participants rated the intensity of the five tastes. The results showed that increasing the sugar concentration in iced tea reduced the sour perception in this product. However, in mayonnaise, the sweet perception remained stable, even when the acid concentration was increased. Thus, in real foods, taste interactions appear to be not as "simple/linear" as those observed in model solutions and could impact the discrimination thresholds.

This study is part of a European project: OPTIFEL (optimised food for elderly people) which aims to develop innovative fruitand vegetable-based products for elderly people at risk of malnutrition (for more information: www.optifel.eu). In this context, we decided to use apple purées. The objective of this study was to evaluate the gustatory discrimination abilities of elderly people for sweet and sour tastes when tasting apple purées. We hypothesized that a group of elderly people would be less effective at discriminating samples of apple purées compared to a group of young adults (H1). The second hypothesis was that, in complex food matrices, taste interactions could modify discrimination performances (masking effects). In other words, small sugar variations may be more difficult to discriminate at a high level of acid than at a low level of acid and small acid variations may be more difficult to discriminate at a high level of sugar (H2) because of masking effects.

\section{Materials and methods}

\subsection{Products}

\subsubsection{Sample preparation}

The basic purée was an apple purée, commercially available in France (reference: Andros “compote allégée”) which initially con- tained $152 \pm 1 \mathrm{~g}$ of sugar per kilogram of purée (degrees Brix, measured by the refractometric method,) and $4.7 \pm 0.1 \mathrm{~g}$ of malic acid per $\mathrm{kg}$ of purée (measured by the $\mathrm{pH}$-metric method, titration). White caster sugar (sucrose) and powdered malic acid (DL malic acid from AppliChem - Panreac, USP-NF, PRS-Codex, food grade) were added to this basic purée.

An experimental design was built with 20 samples divided into two blocks. A first block of 10 samples was prepared to study sweet discrimination: 5 different concentrations of sucrose $\times 2$ fixed levels of malic acid. The two levels of malic acid (sub-block "al" for "acid low" and sub-block "ah" for "acid high") were designed to study interactions between sweet and sour tastes. A second block of 10 samples was prepared to study sour discrimination abilities: 5 different concentrations of malic acid $\times 2$ fixed levels of sucrose. As previously, the two levels of sucrose (sub-block "sl" for "sugar low" and sub-block "sh" for "sugar high") were designed to study taste interactions. Fig. 1 details all the samples prepared for the study.

\subsubsection{Sample codification}

All samples were codified in the same way: the first letter was for the tastant which varied: "S" stands for sugar variations and " $A$ " for acid variations. The number, from 0 to 4 , was for the intensity of this tastant (from weak to strong). The last two letters were for the other tastant, which did not vary between samples of the same sub-block. All the samples with their respective codes and tastant concentrations are presented in the Fig. 1.

\subsubsection{Sugar and malic acid variations}

In apple purées, we decided to manipulate the sugar and acid concentrations as this is realistic in a professional context. The average sugar concentration was set at $200 \mathrm{~g} / \mathrm{kg}$ in accordance with the mean value found in the literature (Oqali, 2010). Low and high levels of sugar were defined symmetrically around $200 \mathrm{~g} / \mathrm{kg}$; i.e. 160 and $240 \mathrm{~g} / \mathrm{kg}$. Thus, samples covered the "fruit desserts" product range (Ministère de l'Agriculture et de la Pêche., 2007; Oqali,, 2010).

No legislation regulates acid concentration in apple purées. Authors have measured titratable acidity in apple purées (expressed in malic acid equivalents) and shown that it can vary from 2.0 to $8.9 \mathrm{~g} / \mathrm{kg}$ (Briones-Labarca, Venegas-Cubillos, OrtizPortilla, Chacana-Ojeda, \& Maureira, 2011; Keenan, Brunton, Butler, Wouters, \& Gormley, 2011; Keenan, Valverde, Gormley, Butler, \& Brunton, 2012; Landl, Abadias, Sárraga, Viñas, \& Picouet, 2010; Picouet, Landl, Abadias, Castellari, \& Viñas, 2009). In four apple purées, commercially available in France, the highest measured titratable acidity was $7.26 \mathrm{~g}$ of malic acid per kilogram of purée. Taking account of measurements and literature data, the upper limit was rounded to $7.5 \mathrm{~g} / \mathrm{kg}$ and the lower limit to $4.71 \mathrm{~g} / \mathrm{kg}$ (no malic acid addition). This was within the product range without being too acidic, which would have been problematic for elderly people (possible case of heartburn; for complete review see Oliver \& Jill Davies, 2008).

\subsection{Sensory profile}

The twenty samples of apple purée were described by conventional sensory profiling. The panel was composed of 18 trained panellists ( 2 men and 16 women). Since 2010, they have been selected and trained according to the recommendations of AFNOR (1995). To analyse apple purées, panellists were asked to evaluate nine sensory attributes: three taste attributes (sweet, sour, bitter), two textural attributes (fluidity, granularity) and four aromatic attributes (overall aromatic intensity, raw fruit, cooked fruit, oxidised fruit). For each attribute, intensity was evaluated on unstructured line scales using Fizz software (Fizz Réseau by 


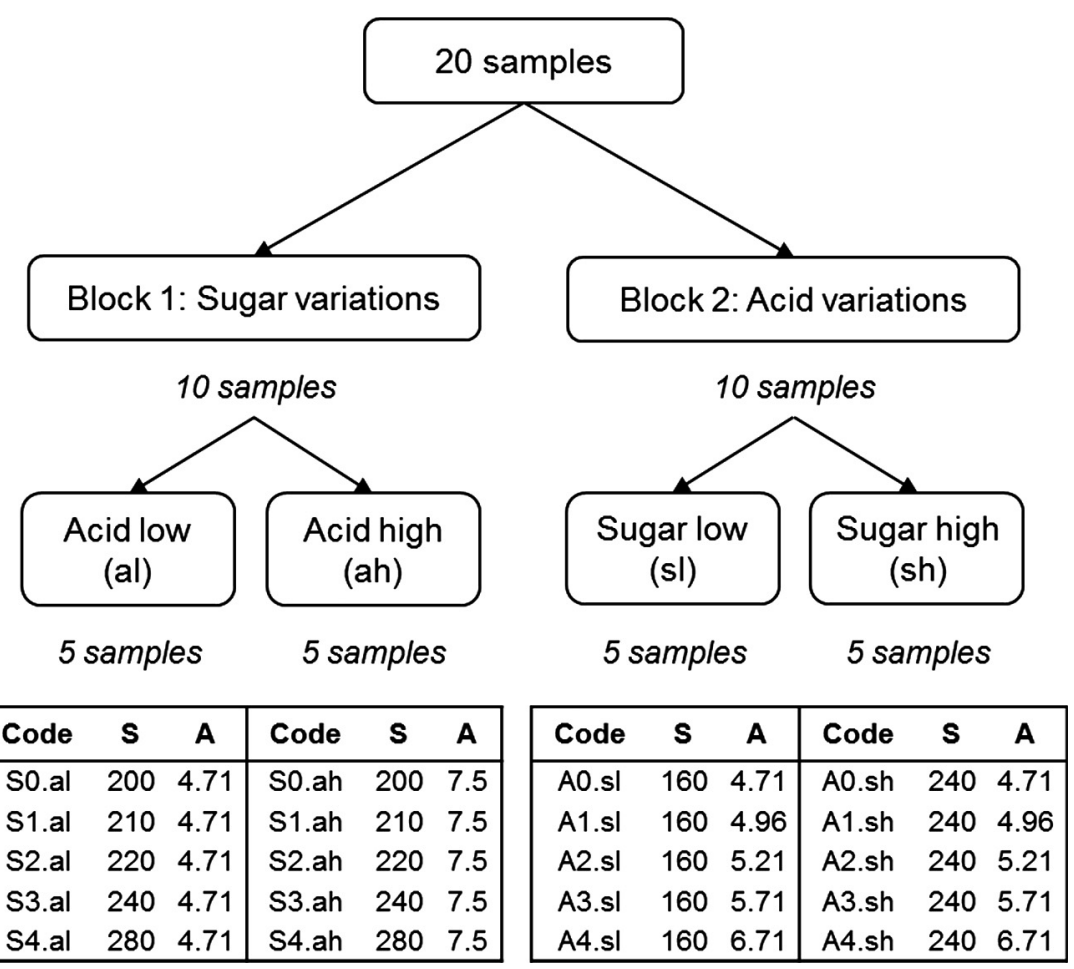

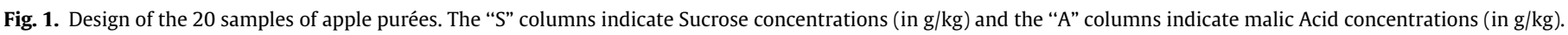

Biosystèmes, version 2.46). Intensity marks varied from 0 (absence of the taste) to 10 (very intense). To prevent an order effect, all samples were presented in a balanced order according to a William's Latin Square. Panellists were required to take a break of two minutes and rinse their mouth with plain water before evaluating the next sample.

\subsection{Discrimination abilities}

\subsubsection{Participants}

A total of 235 participants were recruited in two age groups. First, the "young adults" ( $\mathrm{n}=105,64$ in France and 41 in Poland, 39 and 25 women, respectively) were aged from 18 to 40 yearsold with a mean age of $28 \pm 6$ years (France: $29 \pm 6$ years, Poland: $27 \pm 6$ years). The second age group was the "elderly people" ( $n=130,69$ in France and 61 in Poland, 46 women in each country) who were aged from 65 to 83 years-old with a mean age of $71 \pm 5$ years (in both France and Poland) and still autonomous. Young adults were recruited by mails and autonomous elderly people were recruited by telephone. All participants had to meet the following inclusion criteria: no operation / traumatism / illness that may affect olfaction or gustation, no food allergies, no gastric problems, no problems with sugar consumption and eating apple purées at least once a year. Cognitive status of elderly participants was assessed with the Mini Mental State Examination (MMSE) questionnaire (Folstein, Folstein, \& McHugh, 1975).

\subsubsection{Procedure}

Within each sub-block (al, ah, sl, sh), four pairs were designed and named P1 to P4; P1 being the most difficult to discriminate (very little variation between the samples of the pair). Each pair consisted of: a reference sample (numbered 0) and a comparison sample (numbered from 1 to 4 ). For example, the four pairs presented for sweet discrimination at a low level of acid were: S0. al_S1.al (pair P1); S0.al_S2.al (pair P2); S0.al_S3.al (pair P3) and S0.al_S4.al (pair P4). Each pair was presented twice to participants.
Thus, a total of 32 pairs ( 4 sub-blocks $\times 4$ pairs $\times 2$ replicates) were tasted over the entire experiments ( 4 sessions). One whole subblock ( 4 pairs $\times 2$ replicates) was evaluated in one session. The order of presentation of samples was balanced within each subblock. The sub-block order was balanced over the four sessions. To start each session, the pair P4 was presented to participants as a warm-up (Angulo, Lee, \& O'Mahony, 2007). This pair was the easiest to discriminate and helped people to become familiar with the method and the identification of the targeted taste (sweetness or sourness). For each pair, participants were asked to perform 2-AFC comparison paired tests. They had to taste samples and indicate the sweetest (block 1) or the sourest (block 2) sample. Participants were asked to rinse their mouth with plain water before evaluating the next pair. The number of correct answers was collected for each sub-block and varied from 0 to 8 .

\subsection{Statistical analysis}

Statistical analysis was performed using Statgraphics Centurion XVI (version 16.1.03) and R software (version 3.1.2). All analyses were carried out by sub-block. Intensity scores of sweet and sour tastes from the sensory profile were analysed using analysis of variance (ANOVA) with subjects as random factor, samples as fixed factor and interaction between subjects and samples. When significant, the sample factor was submitted to Honestly Significant Difference (HSD) post hoc tests. To compute individual discrimination scores, all replicates were used (replicates of the same pair were not pooled). Discrimination abilities were analysed with chi2 for the overall level (all pairs pooled) and with a binomial test (Norm NF ISO 5495:2005(F), unilateral paired test) for pair analysis (Chiu, Hewson, Yang, Linforth, \& Fisk, 2015; Mueller, Koehler, \& Scherf, 2016; Scherf, Pflaum, Koehler, \& Hofmann, 2015). Discrimination performances were also assessed using Thurstonian modelling used through $\mathrm{R}$ software (sensR package). The d' (d-prime) values were calculated by pairs for young adults and elderly people and d' comparisons were computed between the two age groups. 


\section{Results}

\subsection{Sensory profile}

3.1.1. Sub-blocks with different sugar concentrations and two levels of acid: Al and ah

ANOVA results showed that the sample effect was significant for both sweet $\left(F_{(9,339)}=21.45, \mathrm{p}<0.001\right)$ and $\operatorname{sour}\left(\mathrm{F}_{(9,339)}=41.24\right.$, $\mathrm{p}<0.001)$ tastes. The subject effect was also significant for sweet $\left(F_{(16,339)}=15.34, \mathrm{p}<0.001\right)$ and sour $\left(F_{(16,339)}=11.84, \mathrm{p}<0.001\right)$ perceptions. On the contrary, in both cases, no significant effect was found for the interaction subjects $\times$ samples (sweet: $\mathrm{p}=0.525$; sour: $\mathrm{p}=0.121$ ). HSD post hoc tests showed no significant difference in sweet perceptions for the closest samples from the al sub-block (S0.al and S1.al) and the ah sub-block (S0.ah and S1.ah) (Table 1 and Fig. 2). Thus, when presented in pairs, these samples were expected to be difficult to discriminate. Our results confirm a sensory sweet-sour interaction: sugar additions increased sweet and decreased sour perceptions ( $\mathrm{S} 4$ was perceived as sweeter and less sour than S1). Samples with a high level of acid (ah) were perceived as sourer than samples with a low level of acid (al). With a high level of acid, samples were perceived as less sweet than with a low level of acid, but the difference was not significant.

Sensory profile also revealed that sugar additions was linked to aromatic modifications. Compared to the reference (SO), the sweetest samples (A4) were described to have a higher global aroma intensity, to be more "cooked fruit" and less "oxidised fruit" ( $p<0.01$ or lower). The sourest samples (A4) were described to be more "raw fruit" and more "oxidised fruit" $(\mathrm{p}<0.001)$. These attributes were only significantly different between the references ( $\mathrm{S} 0$ and $\mathrm{A} 0$ ) and the most intense samples ( $\mathrm{S} 4$ and A4). No significant differences were found by trained panellists between samples presented in a monadic sequential manner with less intense samples (S1, S2 or A1, A2).

\subsubsection{Sub-blocks with different acid concentrations and two levels of} sugar: Sl and sh

As for the previous sub-block, ANOVA results revealed significant effects for the sample (sweet: $F_{(9,339)}=66.03, p<0.001$; sour: $\left.F_{(9,339)}=9.95, p<0.001\right)$ and for the subjects (sweet: $\mathrm{F}_{(16,339)}=11.25, \mathrm{p}<0.001$; sour: $\left.\mathrm{F}_{(16,339)}=9.59, \mathrm{p}<0.001\right)$. The subjects $\times$ sample interaction was significant for sour $\left(F_{(144,339)}=1.83, p<0.001\right)$ but not for sweet $\left(F_{(144,339)}=1.04\right.$, pgreater than 0.05 ) perceptions. HSD post hoc tests showed no significant difference in sour perceptions for the closest samples from the sl sub-block (A0.sl and A1.sl) and the sh sub-block (A0.sh and A1.sh) (Table 1 and Fig. 2). The discrimination of these samples were expected to be difficult. As in paragraph 3.1.1, our results confirm a sensory sour-sweet interaction: with acid additions, sour perceptions increased and sweet perceptions decreased (A4 was perceived as sourer and less sweet than A1). Samples with a high level of sugar (sh) were perceived as sweeter and less sour than samples with a low level of sugar (sl).

\subsection{Discrimination abilities}

\subsubsection{Cognitive status of elderly participants}

Participants with MMSE scores lower than 21/30 were not included (Laureati, Pagliarini, Calcinoni, \& Bidoglio, 2006). Mean MMSE scores were higher than $28 / 30$ in France $(28.8 \pm 1.2)$ and in Poland (28.1 \pm 2.2 ), assuring that elderly participants were cognitively able to answer questionnaires and perform pair tests.

\subsubsection{Discrimination abilities per subject}

To analyse discrimination performances at an overall level, the numbers of correct answers for all pairs were pooled by sub-block. Regarding the number of correct answers, no significant differences were found between countries for sweet $\left(\mathrm{chi}^{2}=0.0299\right.$, $\mathrm{p}=0.8627$ ) or sour $\left(\mathrm{chi}^{2}=0.1215, \mathrm{p}=0.7274\right)$ discrimination tests. Thus, participants from both countries were regrouped for further analysis. Comparing the numbers of correct answers of elderly people to those of young adults (see Table 2), no significant differences were found for sweet $\left(\mathrm{chi}^{2}=0.0357, \mathrm{p}=0.8502\right)$ or sour $\left(\mathrm{chi}^{2}=0.2705, \mathrm{p}=0.6030\right)$. Taste interactions and masking effects did not seem to impact the discrimination performances of participants: correct answers for sweet discrimination did not decrease at a high level of acid, and correct answers for sour discrimination did not decrease at a high level of sugar.

\subsubsection{Discrimination abilities - are all pairs significantly discriminated?}

We deliberately designed four pairs with increasing difficulty to discriminate; $\mathrm{P} 1$ was the most difficult to discriminate with a sugar difference of $10 \mathrm{~g} / \mathrm{kg}$ or a malic acid difference of $0.25 \mathrm{~g} / \mathrm{kg}$. Within each sub-block, data were analysed per pair. For both groups, the percentages of wrong answers increased when the proximity of samples increased. There were between $2 \%$ and $6 \%$ of failures for pair P4 (difference of $80 \mathrm{~g} / \mathrm{kg}$ of sucrose or $2 \mathrm{~g} / \mathrm{kg}$ of malic acid) and these reached more than $26 \%$ for pair P1 (difference of $10 \mathrm{~g} / \mathrm{kg}$ of sucrose or $0.25 \mathrm{~g} / \mathrm{kg}$ of malic acid). However, according to Norm NF ISO 5495:2005(F) on paired comparison tests, all pairs were significantly discriminated at a significance level of 0.001 (number of correct answers greater than 128 for young adults and 156 for elderly people). Exact p-values were calculated for each pair using the binomial test procedure from $\mathrm{R}$ (see Tables 3 and 4). Young adults group and elderly people group were able to discriminate significantly all samples $(\mathrm{p}<0.001$ for each pair), even those from pair P1. Small sugar variations were not more difficult to discriminate at a high level of acid and small acid variations were not more difficult to discriminate at a high level of sugar. Fig. 3 and Fig. 4 represent the percentages of success and error for each pair and each age group.

Table 1

Mean values (0-10) given by the trained sensory panel for sweet and sour perceptions in apple purées.

\begin{tabular}{|c|c|c|c|c|c|}
\hline Sample & Sweet & Sour & Sample & Sweet & Sour \\
\hline S0.al & 5.7 & 3.4 & A0.sl & 3.4 & 4 \\
\hline S1.al & 6.3 & 3.6 & A1.sl & 3.8 & 4.4 \\
\hline S2.al & 6.4 & 3.2 & A2.sl & 3.4 & 5.1 \\
\hline S3.al & 8 & 2.4 & A3.sl & 3.3 & 5.8 \\
\hline S4.al & 8.5 & 2.6 & A4.sl & 2.7 & 6.7 \\
\hline S0.ah & 5.2 & 7.1 & A0.sh & 7.8 & 2.6 \\
\hline S1.ah & 5.9 & 7.1 & A1.sh & 7.6 & 3.4 \\
\hline S2.ah & 6.1 & 7 & A2.sh & 7.9 & 4 \\
\hline S3.ah & 7.5 & 6.4 & A3.sh & 7.7 & 4.2 \\
\hline S4.ah & 8.3 & 6.1 & A4.sh & 7.4 & 5.3 \\
\hline
\end{tabular}




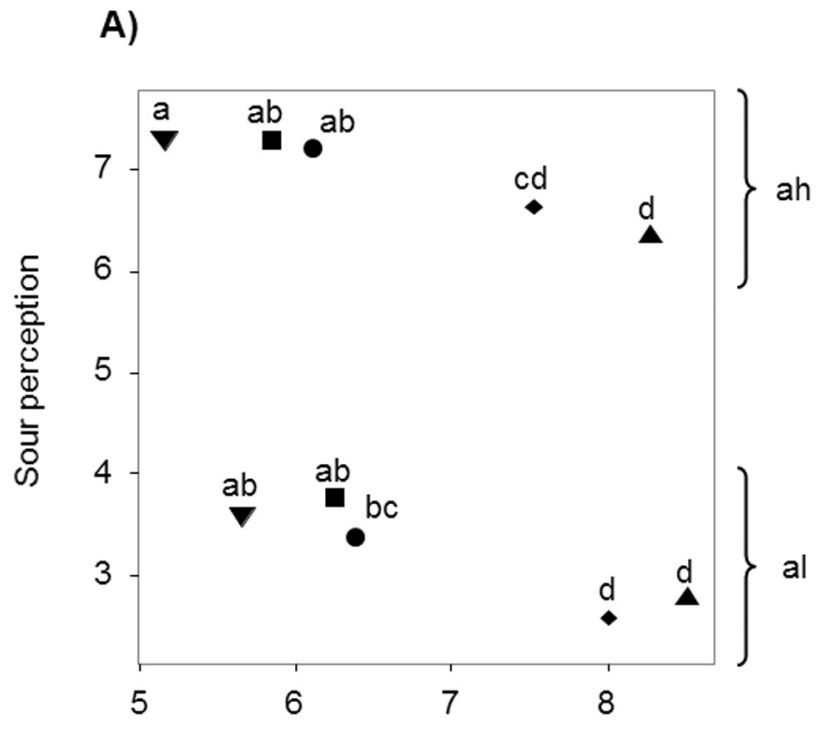

Sweet perception

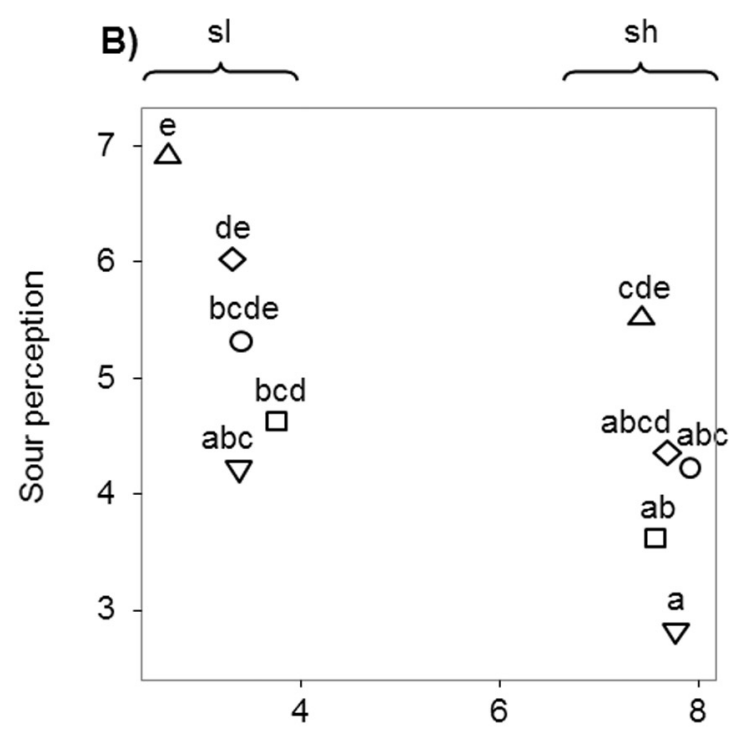

Sweet perception

\section{so 1

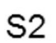 \\ S3 \\ S4}

\section{$\triangle \mathrm{A} 4$}

Fig. 2. Sensory profile results for sweet and sour tastes (real perceived intensities). Letters represent HSD homogeneous groups on sweet perception (A) or on sour perception (B). Symbols represent apple purée samples.

Table 2

Percentages of correct answers, given by age group for discrimination of sweet and sour tastes at a low and high level of acid and sugar in apple purée.

\begin{tabular}{llll}
\hline & & Elderly people & Young adults \\
\hline A) & al & 84.7 & 85.0 \\
& ah & 83.4 & 85.0 \\
B) & sl & 84.1 & 83.1 \\
& sh & 82.1 & 84.4 \\
\hline
\end{tabular}

A: sweet discrimination at a low level of acid (al) and a high level of acid (ah). $\mathrm{B}$ : sour discrimination at a low level of sugar ( $\mathrm{sl}$ ) and a high level of sugar ( $\mathrm{sh}$ ).

\section{Discussion}

The present study investigated discrimination abilities in a real food matrix: apple purée. Our findings provide complementary results about the preservation of discrimination abilities of elderly people in real products. We showed that the group of elderly people was as effective as the group of young adults in differentiating apple purée samples, based on sugar or acid differences of at least $10 \mathrm{~g} / \mathrm{kg}$ or $0.25 \mathrm{~g} / \mathrm{kg}$, respectively. In previous studies on model solutions, researchers showed that the discrimination abilities of elderly people were preserved for sweet but not for bitter perceptions (Gilmore \& Murphy, 1989) and, more recently, preserved for the five tastes (Mojet et al., 2003). In 2003, Mojet et al. drew the same conclusions for real food matrices (iced tea, chocolate drink, mayonnaise, tomato soup and bouillon). The lowest variations discriminated were $11.09 \mathrm{~g} / \mathrm{l}$ for sucrose and $0.069 \mathrm{~g} / \mathrm{l}$ (acetic acid) or $0.005 \mathrm{~g} / \mathrm{l}$ (citric acid). In 1989, CoSeteng, McLellan, \& Downing compared the perceived sourness of different acids and showed that, at the same concentration, malic acid was perceived as less sour than acetic acid but sourer than citric acid (CoSeteng, McLellan and Downing, 1989). Moreover, overall taste concentrations were different between experiments. While we used samples with $200-210 \mathrm{~g} / \mathrm{kg}$ of sucrose or $4.71-4.96 \mathrm{~g} / \mathrm{kg}$ of malic acid, Mojet et al. used samples with $42.9-53.9 \mathrm{~g} / \mathrm{kg}$ of sucrose, $0.27-$ $0.34 \mathrm{~g} / \mathrm{kg}$ of acetic acid or $0.019-0.024 \mathrm{~g} / \mathrm{kg}$ of citric acid. Our results thus complement those of Mojet et al. in real products with the addition of malic acid and by exploring a lower variation of sucrose.

Real foods involve taste interactions. Our experimental design also allowed us to study the impact of malic acid concentrations on sweet discrimination and the impact of sucrose concentrations on sour discrimination. Even though the sensory profile confirmed

Table 3

Number of correct answers, associated level of significance and d' values, for sweet discrimination at a low level of acid (al) and a high level of acid (ah) in apple purées

\begin{tabular}{|c|c|c|c|c|c|c|}
\hline & \multirow[t]{2}{*}{ Pairs } & \multicolumn{2}{|l|}{ Young adults $(\mathrm{n}=210)$} & \multicolumn{2}{|c|}{ Elderly people $(\mathrm{n}=260$ ) } & \multirow{2}{*}{$\begin{array}{l}\mathrm{d}^{\prime} \text { comparison } \\
\text { p-value }\end{array}$} \\
\hline & & $\mathrm{n}$ of correct answers & $\mathrm{d}^{\prime}$ & $\mathrm{n}$ of correct answers & $\mathrm{d}^{\prime}$ & \\
\hline \multirow[t]{4}{*}{ al } & P1 & $142^{* * * * *}$ & 0.65 & $180^{* * * *}$ & 0.71 & 0.71 \\
\hline & $\mathrm{P} 2$ & $172^{* * * * *}$ & 1.29 & $205^{* * * *}$ & 1.13 & 0.41 \\
\hline & P3 & $195^{* * * * *}$ & 2.07 & $244^{* * * * *}$ & 2.18 & 0.67 \\
\hline & P4 & $205^{* * * *}$ & 2.80 & $252^{* * * * *}$ & 2.64 & 0.64 \\
\hline \multirow[t]{4}{*}{ ah } & P1 & $148^{* * * * *}$ & 0.76 & $181^{* * * * *}$ & 0.73 & 0.84 \\
\hline & $\mathrm{P} 2$ & $171^{* * * * *}$ & 1.26 & $207^{* * * *}$ & 1.17 & 0.62 \\
\hline & P3 & $193^{* * * * *}$ & 1.98 & $235^{* * * *}$ & 1.84 & 0.56 \\
\hline & P4 & $202^{* * * * *}$ & 2.51 & $244^{* * * * *}$ & 2.18 & 0.24 \\
\hline
\end{tabular}


Table 4

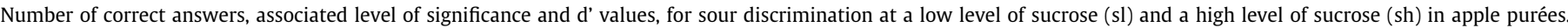

\begin{tabular}{|c|c|c|c|c|c|c|}
\hline & \multirow[t]{2}{*}{ Pairs } & \multicolumn{2}{|c|}{ Young adults $(n=210)$} & \multicolumn{2}{|c|}{ Elderly people $(n=260)$} & \multirow{2}{*}{$\begin{array}{l}\text { d' comparison } \\
\text { p-value }\end{array}$} \\
\hline & & $\mathrm{n}$ of correct answers & $d^{\prime}$ & $\mathrm{n}$ of correct answers & $\mathrm{d}^{\prime}$ & \\
\hline \multirow[t]{4}{*}{ sl } & P1 & $135^{* * * *}$ & 0.52 & $192^{* * * * *}$ & 0.90 & 0.025 " \\
\hline & P2 & $168^{* * * *}$ & 1.19 & $200^{* * * *}$ & 1.04 & 0.42 \\
\hline & P3 & $193^{* * * *}$ & 1.98 & $236^{* * * * *}$ & 1.88 & 0.66 \\
\hline & $\mathrm{P} 4$ & $202^{* * * *}$ & 2.51 & $247^{* * * * *}$ & 2.33 & 0.53 \\
\hline \multirow[t]{4}{*}{ sh } & P1 & $137^{* * * *}$ & 0.55 & $180^{* * * * *}$ & 0.71 & 0.36 \\
\hline & $\mathrm{P} 2$ & $165^{* * * * *}$ & 1.12 & $196^{* * * * *}$ & 0.97 & 0.41 \\
\hline & P3 & $202^{* * * *}$ & 2.51 & $228^{* * * *}$ & 1.64 & $0.001^{* * *}$ \\
\hline & $\mathrm{P} 4$ & $205^{* * * *}$ & 2.80 & $250^{* * * * *}$ & 2.50 & 0.36 \\
\hline
\end{tabular}

$\mathrm{p}<0.0001$

*** $\mathrm{p}<0.001$

$\mathrm{p}<0.05$
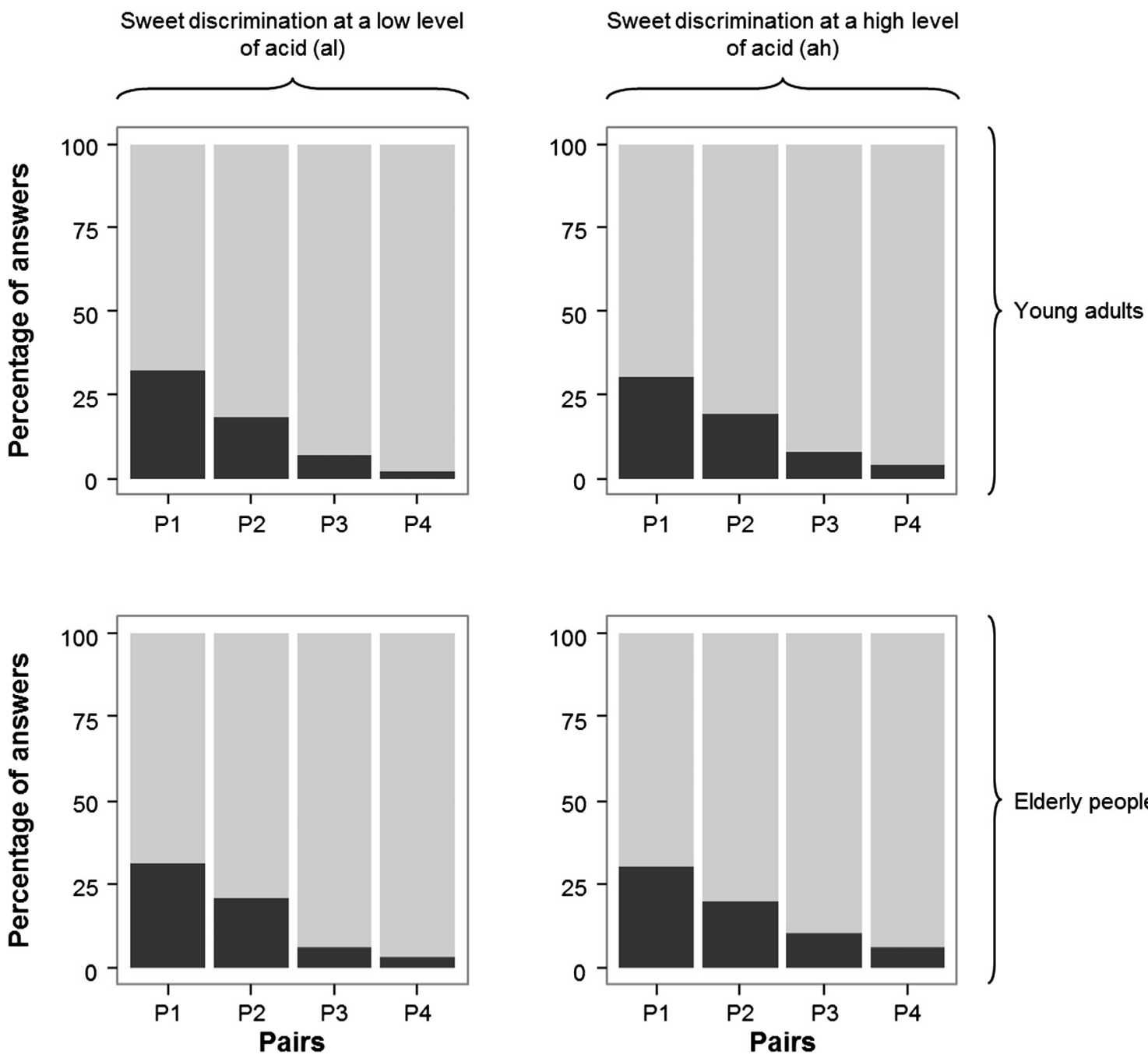

Elderly people

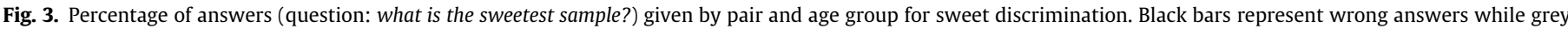

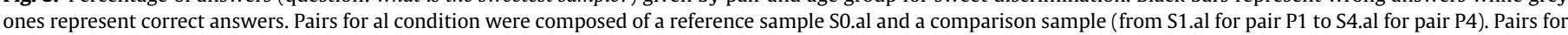
ah condition were composed of a reference sample S0.ah and a comparison sample (from S1.ah for pair P1 to S4.ah for pair P4).

a sensory sweet-sour interaction, no effect of these interactions was found on discrimination abilities in our conditions. A difference of $10 \mathrm{~g} / \mathrm{kg}$ of sucrose was significantly discriminated by the elderly people group at either a low level $(4.71 \mathrm{~g} / \mathrm{kg})$ or a high level $(6.71 \mathrm{~g} / \mathrm{kg}$ ) of malic acid. Similarly, the elderly people group was able to discriminate significantly samples with a malic acid variation of $0.25 \mathrm{~g} / \mathrm{kg}$, at either a low level $(160 \mathrm{~g} / \mathrm{kg})$ or a high level
$(240 \mathrm{~g} / \mathrm{kg}$ ) of sucrose. In 2000, Kaneda et al. compared the discrimination abilities of 20 elderly people and 20 young adults using sweet-sour model solutions. Participants evaluated mixtures in which both compounds (sucrose and tartaric acid) varied between samples. Their results showed that the elderly people group was able to discriminate samples with variations of $34.57 \mathrm{~g} / \mathrm{kg}$ of sucrose and $0.11 \mathrm{~g} / \mathrm{kg}$ of tartaric acid but not with variations of 
Sour discrimination at a low level of sucrose $(\mathrm{sl})$
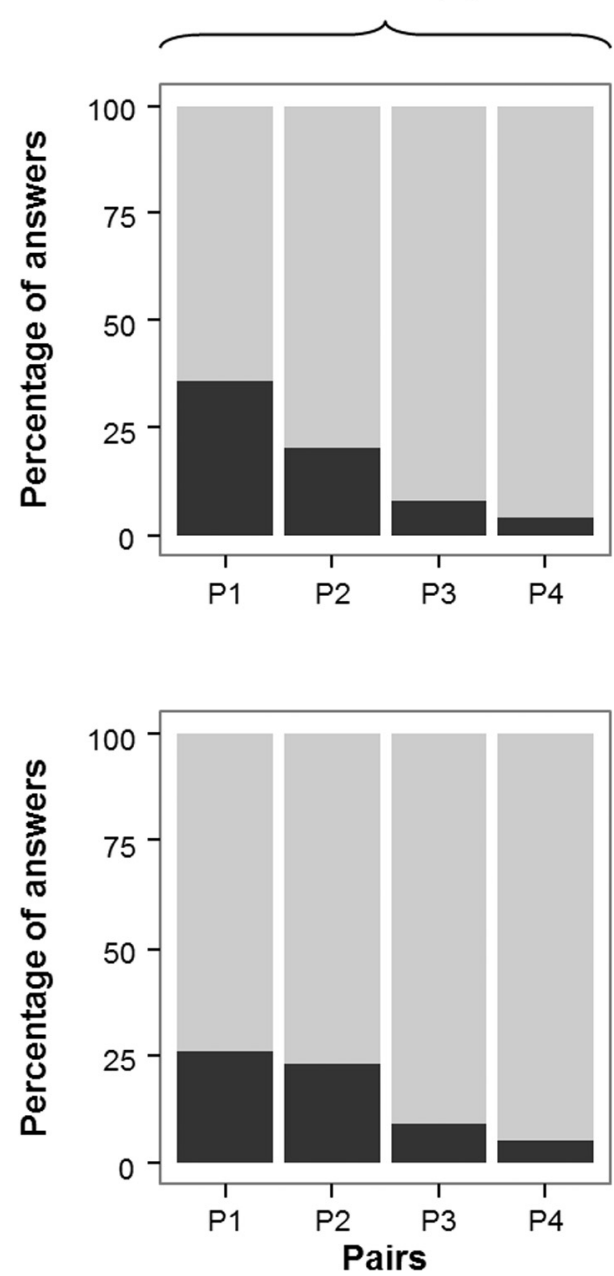

Sour discrimination at a high level of sucrose (sh)
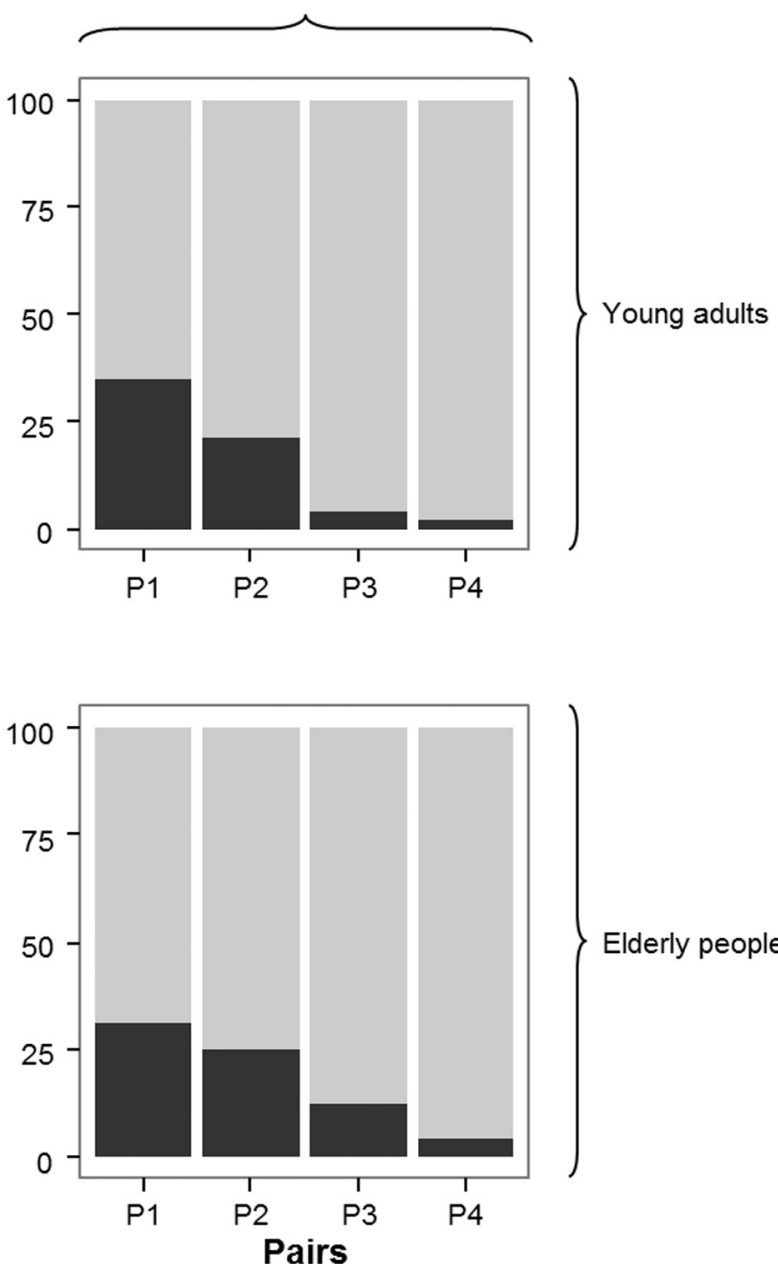

Elderly people

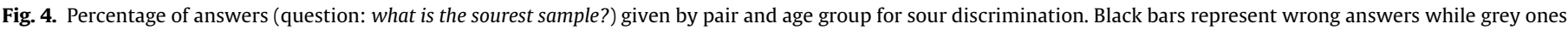

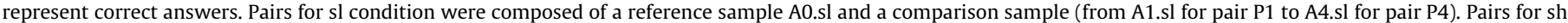
condition were composed of a reference sample A0.sh and a comparison sample (from A1.sh for pair P1 to A4.sh for pair P4).

$16.77 \mathrm{~g} / \mathrm{kg}$ of sucrose and $0.057 \mathrm{~g} / \mathrm{kg}$ of tartaric acid. As both tastes varied at the same time, no conclusion can be drawn for only sucrose or acid. In our study, we used specific tests to measure sweet and sour discrimination performances independently (only one taste varied between samples) and to conclude on each taste independently.

It is noted that other sensory clues, apart from sweet and sour variations, may have helped participants to discriminate apple purées. For example, the sensory profile revealed that sugar and/ or acid additions were linked to aromatic modifications. These sensory modifications may have helped participants to discriminate samples. However, these attributes were only significant between the references and the most intense samples. No significant difference was found by trained panellists, in monadic sequential, with less intense samples (S1, S2 or A1, A2). However, in comparison tests, these slight sensory modifications in aroma may have been wide enough to help participants to differentiate apple purées, in addition with sweet or sour variations.

The procedure used to measure discrimination abilities can also be discussed. We decided to use 2-AFC paired comparison tests, which could seem too "easy" (one chance in two of finding the correct answer). Recently, some authors have challenged the methodologies used with elderly people and have recommended replacing triangle or tetrad tests by duo-trio or paired comparison tests. These are more adapted to the frailty, limited attention and limited working memory of the elderly (Issanchou, 2015; Maitre, Symoneaux, \& Sulmont-Rossé, 2015). Moreover, comparing the power of different discrimination tests (2-AFC, 3-AFC, 10-AFC and specified tetrad) as a function of sample size, authors concluded that "the methods perform very similarly" (Ennis \& Jesionka, 2011). In their experiments, Kaneda et al. (2000) and Mojet et al. (2003) used triangle tests. More experiments are needed to conclude which methodology is the most accurate and best fits the abilities of this specific population.

Another question is: were the differences between samples too wide and the samples too easy to differentiate to highlight differences between the performances of elderly and young people? Samples from pair P1 were designed to be very close in terms of sweet and sour perceptions. Trained panellists did not give significantly different sweet and sour notes for the two samples from this pair. As the sensory profile is a sequential monadic evaluation, it is less efficient for discriminating samples than difference tests but these results support the hypothesis that the samples from pair P1 were very close to each other. The sensory profile results also showed that increasing sugar concentration tends to decrease sour perception, at either a low or a high level of acid. Increasing malic 
acid concentration tends to decrease sweet perception, but only at a low level of sugar. These results support conclusions in the literature showing that sweet and sour tastes have mutual masking effects (Pelletier et al., 2004; Stevens, 1996) which are concentration-dependent (for a complete review, see Keast and Breslin (2002). Regarding pair P1, d' values were low (0.52 for the lowest). Despite no significant difference for pair P1, d' values for young adults were found to be lower than d' values for elderly participants (except for sour discrimination at a low level of sugar). Thus, even with small sugar or acid variations, discrimination performances were at least equivalent between young adults and elderly participants. Moreover, this study is part of a European project (OPTIFEL) which aims to develop fruit- and vegetable-based products for elderly people. The smallest sugar or acid variations thus matched with "realistic" variations that could occur in food industries ( $10 \mathrm{~g} / \mathrm{kg}$ of sugar or $0.25 \mathrm{~g} / \mathrm{kg}$ of malic acid). In previous bibliography, d' values are often compared between difference tests (Ennis \& Jesionka, 2011; McClure \& Lawless, 2010; Van Hout, Hautus, \& Lee, 2011). However, little is known about d' comparisons between different samples. In 2011, Van Hout et al. compared two commercial margarine products. The authors ran a preliminary study to be sure that the two products were "sufficiently confusable in overall sensory properties to be appropriate for the study". Results showed that, at the first two sessions, the d' value was 0.58 (2-AFC procedure). With regards to product specificity, these results give an insight into d' values that could be found between two commercial products. It could be interesting to test smaller variations between samples in order to identify the differentiation threshold for each compound. However, such small sugar or acid variations (lower than $10 \mathrm{~g} / \mathrm{kg}$ or $0.25 \mathrm{~g} / \mathrm{kg}$ ) would not be realistic to achieve in terms of industrial production and not of direct relevance for the food industry.

\section{Conclusion}

The present study provides original findings about the ability of elderly people to discriminate sweetness and sourness in real foods. Discrimination performances for sweet and sour tastes seem to be relatively stable with age. Elderly people were still able to differentiate sweetness and sourness concentrations in products. Moreover, in our experimental conditions, no masking effects were found between sweet and sour tastes. These results give flexibility and opportunities to the food industry in developing fruit-based products.

\section{Acknowledgement}

The research leading to these results received funding from the European Union Seventh Framework Programme for research, technological development and demonstration under grant agreement $n^{\circ} 311754$ (for OPTIFEL). This project also received funding from the Pays de la Loire Region. Authors would like to thank C. Patron for training the expert panellists and conducting the sensory profiles. All the partners and interviewers involved in this study are also acknowledged for their involvement and field work. Finally, special thanks are addressed to Carol Robins for her help in English revision and to all the participants for their time and valuable answers.

\section{References}

AFNOR (1995). V 09-021. Analyse sensorielle - Recherche et sélection de descripteurs pour l'élaboration d'un profil sensoriel, par approche multidimensionnelle. In AFNOR (Ed.), Contrôle de la qualité des produits alimentaires - Analyse sensorielle (5th ed., pp. 276-310). Paris.

Angulo, O., Lee, H.-S., \& O'Mahony, M. (2007). Sensory difference tests: Overdispersion and warm-up. Food Quality and Preference, 18(2), 190-195.
Briones-Labarca, V., Venegas-Cubillos, G., Ortiz-Portilla, S., Chacana-Ojeda, M., \& Maureira, H. (2011). Effects of high hydrostatic pressure (HHP) on bioaccessibility, as well as antioxidant activity, mineral and starch contents in Granny Smith apple. Food Chemistry, 128(2), 520-529.

Chiu, N., Hewson, L., Yang, N., Linforth, R., \& Fisk, I. (2015). Controlling salt and aroma perception through the inclusion of air fillers. LWT - Food Science and Technology, 63(1), 65-70.

CoSeteng, M. Y., McLellan, M. R., \& Downing, D. L. (1989). Influence of titratable acidity and ph on intensity of sourness of citric, malic, tartaric, lactic and acetic acids solutions and on the overall acceptability of imitation apple juice. Canadian Institute of Food Science and Technology Journal, 22(1), 46-51.

Doty, R. L., Shaman, P., Applebaum, S. L., Giberson, R., Siksorski, L., \& Rosenberg, L. (1984). Smell identification ability: Changes with age. Science (New York, N.Y.), 226(4681), 1441-1443.

Ennis, J. M., \& Jesionka, V. (2011). The power of sensory discrimination methods revisited. Journal of Sensory Studies, 26(5), 371-382.

Folstein, M. F., Folstein, S. E., \& McHugh, P. R. (1975). Mini-mental state: A practical method for grading the cognitive state of patients for the clinician. Journal of Psychiatric Research, 12(3), 189-198.

Gilmore, M. M., \& Murphy, C. (1989). Aging is associated with increased Weber ratios for caffeine, but not for sucrose. Perception \& Psychophysics, 46(6), $555-559$.

Green, B. G., Lim, J., Osterhoff, F., Blacher, K., \& Nachtigal, D. (2010). Taste mixture interactions: suppression, additivity, and the predominance of sweetness. Physiology \& Behavior, 101(5), 731-737.

Issanchou, S. (2015). Sensory \& consumer studies with special populations: children and elderly. Current Opinion in Food Science, 3, 53-58.

Kaneda, H., Maeshima, K., Goto, N., Kobayakawa, T., Ayabe-Kanamura, S., \& Saito, S. (2000). Decline in taste and odor discrimination abilities with age, and relationship between gustation and olfaction. Chemical Senses, 25(3), 331-337.

Keast, R. S. J., \& Breslin, P. A. S. (2002). An overview of binary taste-taste interactions. Food Quality and Preference, 14(2), 111-124.

Keenan, D. F., Brunton, N. P., Butler, F., Wouters, R., \& Gormley, R. (2011). Evaluation of thermal and high hydrostatic pressure processed apple purees enriched with prebiotic inclusions. Innovative Food Science E' Emerging Technologies, 12(3), 261-268.

Keenan, D. F., Valverde, J., Gormley, R., Butler, F., \& Brunton, N. P. (2012). Selecting apple cultivars for use in ready-to-eat desserts based on multivariate analyses of physico-chemical properties. LWT - Food Science and Technology, 48(2) 308-315.

Kremer, S. (2008). Food perception and food liking with age. Thesis: Wageningen University.

Kremer, S., Bult, J. H. F., Mojet, J., \& Kroeze, J. H. A. (2007). Food perception with age and its relationship to pleasantness. Chemical Senses, 32(6), 591-602.

Landl, A., Abadias, M., Sárraga, C., Viñas, I., \& Picouet, P. A. (2010). Effect of high pressure processing on the quality of acidified Granny Smith apple purée product. Innovative Food Science E Emerging Technologies, 11(4), 557-564.

Laureati, M., Pagliarini, E., \& Calcinoni, O. (2006). Bidoglio M, Sensory acceptability of traditional food preparations by elderly people. Food Quality and Preference. 17(1-2), 43-52.

Maitre, I., Symoneaux, R., \& Sulmont-Rossé, C. (2015). Sensory testing in new product development: working with older people. In J. Delarue, J. Ben Lawlor, \& M. Rogeaux (Eds.), Rapid Sensory Profiling Techniques (pp. 485-508). Woodhead publishing (Elsevier).

Methven, L., Allen, V. J., Withers, C. A., \& Gosney, M. A. (2012). Ageing and taste. Proceedings of the Nutrition Society, 71(04), 556-565.

McClure, S., \& Lawless, H. T. (2010). Comparison of the triangle and a self-defined two alternative forced choice test. Food Quality and Preference, 21(5), 547-552.

Ministère de l'Agriculture et de la Pêche. (2007). Rapport du groupe de travail PNNS sur les glucides - Etapes 1 et 2 du mandat.

Mojet, J., Christ-Hazelhof, E., \& Heidema, J. (2001). Taste perception with age: Generic or specific losses in threshold sensitivity to the five basic tastes? Chemical Senses, 26(7), 845-860.

Mojet, J., Heidema, J., \& Christ-Hazelhof, E. (2003). Taste perception with age: Generic or specific losses in supra-threshold intensities of five taste qualities? Chemical Senses, 28(5), 397-413.

Mojet, J., Heidema, J., \& Christ-Hazelhof, E. (2004). Effect of concentration on tastetaste interactions in foods for elderly and young subjects. Chemical Senses, 29(8), 671-681.

Mueller, E., Koehler, P., \& Scherf, K. A. (2016). Applicability of salt reduction strategies in pizza crust. Food Chemistry, 192, 1116-1123.

Murphy, C., Cain, W. S., Gilmore, M. M., \& Skinner, R. (1991). Sensory and semantic factors in recognition memory for odors and graphic stimuli: Elderly versus young persons. The American Journal of Psychology, 104(2), 161-192.

Oliver, K. L., \& Jill Davies, G. (2008). Heartburn: Influence of diet and lifestyle. Nutrition \& Food Science, 38(6), 548-554.

Oqali (2010). Observatoire de la qualité de l'alimentation - Etude sectorielle des compotes Retrieved from https://www.oqali.fr/Publications-Oqali/Etudessectorielles.

Pelletier, C. A., Lawless, H. T., \& Horne, J. (2004). Sweet-sour mixture suppression in older and young adults. Food Quality and Preference, 15(2), 105-116.

Picouet, P. A., Landl, A., Abadias, M., Castellari, M., \& Viñas, I. (2009). Minimal processing of a Granny Smith apple purée by microwave heating. Innovative Food Science \& Emerging Technologies, 10(4), 545-550.

Roberts, S. B., \& Rosenberg, I. (2006). Nutrition and aging: Changes in the regulation of energy metabolism with aging. Physiological Reviews, 86(2), 651-667. 
Scherf, K. A., Pflaum, T., Koehler, P., \& Hofmann, T. (2015). Salt taste perception in hydrocolloid systems is affected by sodium ion release and mechanosensorygustatory cross-modal interactions. Food Hydrocolloids, 51, 486-494.

Schiffman, S. S., \& Pasternak, M. (1979). Decreased discrimination of food odors in the elderly. Journal of Gerontology, 34(1), 73-79.

Schiffman, S. S., Sattely-Miller, E. A., Zimmerman, I. A., Graham, B. G., \& Erickson, R. P. (1994). Taste perception of monosodium glutamate (MSG) in foods in young and elderly subjects. Physiology E' Behavior, 56(2), 265-275.

Stevens, J. C. (1996). Detection of tastes in mixture with other tastes: Issues of masking and aging. Chemical Senses, 21(2), 211-221.

Stevens, J. C., \& Dadarwala, A. D. (1993). Variability of olfactory threshold and its role in assessment of aging. Perception \& Psychophysics, 54(3), 296-302.
Sulmont-Rossé, C., Maitre, I., Amand, M., Symoneaux, R., Van Wymelbeke, V., Caumon, E., \& Ellipsis Issanchou, S. (2015). Evidence for different patterns of chemosensory alterations in the elderly population: Impact of age versus dependency. Chemical Senses, 40(3), 153-164.

Sulmont-Rossé, C., Maitre, I., \& Issanchou, S. (2010). Âge, perception chimiosensorielle et préférences alimentaires. Gérontologie et société, 134(3), 87.

Van Hout, D., Hautus, M. J., \& Lee, H.-S. (2011). Investigation of test performance over repeated sessions using signal detection theory: Comparison of three nonattribute-specified difference tests 2-AFCR, A-Not A and 2-AFC. Journal of Sensory Studies, 26(5), 311-321. 